\title{
Pollution is Always with Us
}

Oxe cynical but not necessarily misguided view of the wave of concern about the condition of the environment is that it has served marvellously to concentrate the interest of university students on issues other than student power or the supposed lack of it. A year ago, the young people at San José State College in California, who buried a brand new motor car in a hole in the ground as a symbol of their devotion to clean air, might well have been scrawling obscenities on the walls of university administration buildings or pelting administrators themselves with various kinds of food. It is true. of course, that the young people's passion may simply be another way of protesting that older generations have made a mess of things, but even this is probably irrelevant. And the fact remains that young people are not alone in their devotion to environmental causes. Whatever public policies eventually emerge from all the present excitement, it is an important question to know why there has been such a rapid growth of concern about the environment.

The notion that the photographs of the Earth returned by the Apollo astronauts have served to emphasize what a fragile place the Earth must be has been widelv canvassed, most eloquently perhaps by Professor Fred Hoyle at the Houston conference about the Moon in January. No doubt there is something in this. although the Apollo photographs have probably done more to rationalize and make explicit a tendency which must already have been well under way. Indeed, both in western Europe and the United States, the origins of the present concern about the environment have been evident for several years. The smog over Los Angeles became in the sixties what the cloud of smoke over Pittsburgh used to be in the days before clean air legislation, and served as a focus for legislation about motor vehicle exhausts. In Britain, the condition of the Thames became first a public scandal and then an incentive for the kinds of administrative actions which have now helped to make the river almost tolerable. In the same way, the Rhine has been the chief stimulus to the development of regulations for international waterways. It is, in circumstances like these, something of a surprise that public anxiety of the kind which has now led to the creation of a standing Royal Commission in Britain, a Federal Council on the Environment in the United States, and a permanent organization within OECD should have come to a head in such a dramatic way. Is it that there really is a crisis around the corner?

The importance of a level headed appraisal of the threats to the environment is that exaggeration either way is likely to be damaging. This, for example, is what seems to have happened with the hasty ban on cyclamates at the end of 1969-exaggerated solicitude for the environment has engendered disbelief. In exactly the same way, the talk now widely to be heard of "environmental crisis" is likely to do more harm than good. The truth is that the environment is a good deal better now than it used to be for those generations which were decimated by tuberculosis and even scarlet fever as recently as the $1930 \mathrm{~s}$. And even now, a great many populations live in circumstances in which the most serious scourges-malaria, for example-must be fought with means such as DDT which are now considered to be polluting in Britain, the United States, Canada and Sweden. One man's potential crisis is, in other words, another's potential salvation. Exaggeration of the threat to the environment, however valuable as a means of concentrating public energy, will therefore smack of what used to be called "neocolonialism" if advanced societies are not careful. Worse still, too simple a view of what the danger is may seriously hamper attempts to get the cleanest environment for the least money.

In these circumstances, there are a great many things which responsible societies could do to improve their environment by simple and comparatively cheap devices. In Britain, the Clean Air Acts have done a lot to improve conditions in the large cities, even though their enforcement leaves a lot to be desired. There is obviously plenty of scope for clean water legislation. On the mainland of Europe and in the United States, geographical size has complicated many problems, but it is still a mystery that opportunities for straightforward remedial legislation are so consistently ignored. In the United States, for example, raw sewage is still discharged into open rivers either in defiance of regulations or with impunity. Although research is at once necessary and interesting, there is no reason why advanced societies should not be able to make respectable progresis towards a more carefully controlled environment by the use of simple administrative devices. The international problem is more serious, if only because international agreements are inherently hard to achieve. Governments will doubtless try to negotiate, for cases such as the Torrey Canyon wrecking, agreements similar to those which regulate insurance against radioactive accidents at nuclear power plants. But issues like that are bound to take years to resolve. The institutions, both national and international, which will eventually be needed for regulating the environment will similarly be slow to emerge. This is why it would be best if some of the red hot passion about the environmental crisis could be converted into a more durable form even if one result might be a resurgence of the interest of students in conditions on the campus. 